\title{
Factors that Influence Canadian Generalist and Physical Education Specialist Elementary School Teachers' Practices in Physical Education: A Qualitative Study
}

Stephanie Truelove

University of Western Ontario

Brianne A. Bruijns

University of Western Ontario

Andrew M. Johnson

University of Western Ontario

Shauna M. Burke

University of Western Ontario

Patricia Tucker

University of Western Ontario 


\begin{abstract}
Interviews were conducted with 16 elementary school teachers across Canada (eight generalists and eight physical education [PE] specialists) to explore their experiences when instructing PE. Questions were phrased to encourage exploration of the perspectives of generalists and specialists, with a particular focus on teaching philosophy, barriers faced while instructing PE, facilitators and resources that enhance PE instruction, and the teachers' self-efficacy when teaching PE. Generalists noted perceived lack of time, inadequate facilities and equipment, insufficient training, lack of knowledge, and low self-efficacy as barriers. Conversely, specialists noted that their advanced training, professional development opportunities, high self-efficacy, and technology use positively supported their teaching practices.
\end{abstract}

Keywords: physical education, elementary school, generalist, specialist, physical activity

\title{
Résumé
}

Des entrevues menées auprès de 16 enseignants du primaire à travers le Canada (huit généralistes et huit spécialistes de l'éducation physique [ÉP]) ont permis d'explorer leurs expériences lors de l'enseignement de l'ÉP. Les questions ont été formulées de manière à explorer les perspectives des généralistes et des spécialistes, en mettant l'accent sur : la philosophie de l'enseignement; les obstacles rencontrés lors de l'enseignement de l'ÉP ; les facilitateurs et les ressources qui améliorent l'enseignement de l'ÉP ; et leur efficacité personnelle dans l'enseignement de l'ÉP. Les généralistes ont indiqué le manque de temps, les installations et les équipements inadéquats, le manque de formation et de connaissance, ainsi qu'une faible efficacité personnelle comme des obstacles. À l'inverse, les spécialistes ont révélé que leur formation avancée, leurs opportunités de développement professionnel, leur grande efficacité personnelle et leur utilisation de la technologie soutenaient positivement leurs pratiques d'enseignement.

Mots-clés : éducation physique, école primaire, généraliste, spécialiste, activité physique 


\section{Acknowledgements}

We would like to thank all teachers who participated in this study.

\section{Funding}

This project was funded by the Mitacs Accelerate Program and the GoodLife for Kids Foundation. ST and BAB are supported by an Ontario Graduate Scholarship, and PT is supported by the Ontario Ministry of Research and Innovation Early Researcher Award. 


\section{Introduction}

As children spend a large portion of their waking hours at school, providing opportunities to participate in physical activity while in this setting is critical to ensuring they are accumulating sufficient amounts of activity to benefit their health (Pate et al., 2006). As a mandatory component of the elementary school curriculum in Canada and other countries, physical education (PE) class is an optimal time for children to be active during the school day (National Association for Sport and Physical Education, 2012). It allows for regular and structured opportunities to be active, and provides time for children to become physically literate, developing the fundamental movement skills, knowledge, and attitudes needed to lead a healthy, active lifestyle (Mandigo et al., 2009).

Education in Canada is regulated at the provincial/territorial level, with the Ministry of Education in each province and territory developing its own PE curriculum specific to its particular needs, resources, and policies (Kilborn et al., 2016). Further, at the elementary school level, the qualifications of educators permitted to instruct PE differ among individual school boards within each province/territory (Kilborn et al., 2016). Teacher qualifications in elementary school PE include "generalist" teachers (i.e., those who are not specially trained in PE during pre-service education) and PE "specialist" teachers (i.e., those who received specialized PE training during pre-service education). Compared to generalist teachers, PE specialists have advanced content knowledge in this area, "as they have either majored or minored in [PE] (often 3-5 years) prior to completing their bachelor of education degree, or have received specialized and intense training during their pre-service program" (Mandigo et al., 2004, p. 89). Currently, 53\% of elementary schools in the province of Ontario employ a full- or part-time PE teacher (People for Education, 2018); in Alberta, approximately 33\% of PE classes at the elementary school level are taught by specialists (Thompson et al., 2001). Globally, there is a mixture of generalist and specialist educators teaching elementary school PE classes (Hardman \& Marshall, 2014).

Although only a small percentage of PE specialist teachers are employed as fullor part-time teachersat at the elementary school level within Canada, arguments made by researchers and educators supporting schools employing PE specialists have been continually presented in the literature as a solution to improve the quality of $\mathrm{PE}$ instruction (Buschner, 1984; Davis et al., 2005; McKenzie et al., 1993; Sallis et al., 1997). Students 
who are taught PE by specialists demonstrate significantly higher levels of achievement in regard to motor skills, physical literacy, academic achievement, fitness, and physical activity levels than do those taught by non-specialists (Sallis et al., 1997), and also experience better health outcomes (Telford et al., 2016).

The advanced training that PE specialists receive during their pre-service education programs can contribute to their quality of curricular delivery by heightening their self-efficacy to teach in this environment (Chase et al., 2001). Teacher self-efficacy refers to the extent to which a teacher believes they have the capacity to affect a student's performance (Ashton, 1984) and according to social cognitive theory (Bandura, 1989), self-efficacy is a major determinant underlying behaviour. Within the context of education, studies have found that PE teachers' self-efficacy can affect: students' learning motivation, atmosphere, and satisfaction (Pan, 2014); their commitment to teach, persistence in teaching, use of time providing instruction, and quality of feedback provided to students (Chase et al., 2001); and their ability to prevail when faced with barriers (Barroso et al., 2005). As such, it is important to ensure that elementary teachers are effectual in teaching PE.

Previous research, mostly quantitative in design, suggests that both generalist and PE specialist teachers face barriers when instructing PE; however, it is theorized that the magnitude of the barriers and the influence they have on teaching practices may differ based on the qualifications of the teacher and their perceived self-efficacy. For example, Barroso and colleagues (2005) explored the perceived strength of eight barriers on 596 specialist teachers' ability to instruct quality PE; they reported that the strongest barriers were ones typically outside of their control (e.g., large class sizes, low priority relative to other academic subjects, inadequate indoor facilities). On the contrary, generalist teachers have reported many institutional and teacher-related barriers when instructing PE (e.g., low levels of confidence and lack of training, knowledge, expertise, and qualifications), which can affect their ability to provide a high-quality PE experience for their students (Decorby et al., 2005; Hyndman, 2017a). In fact, generalist teachers may even avoid teaching PE if the perceived barriers are substantial (Faucette et al., 2002).

Ontario Physical and Health Education Association (Ophea) - a non-profit organization that supports health and PE in Ontario — suggests that both generalist and specialist elementary school teachers are capable of delivering quality physical activity initiatives and programs (Ophea, 2016), and resources are accessible for teachers. However, while 
strategies that have been recommended or employed to support teaching in this environment (e.g., workshops, additional equipment) may be beneficial, they do not generally tailor content or training to the specific needs of each type of teacher. A "one model fits all" approach to support generalist and PE specialists instructing PE may not be appropriate, as these teachers have diverse backgrounds, education, training, and teaching philosophies. It is also unclear what types of supports generalist and specialist teachers would most welcome and find beneficial to improve their self-efficacy in teaching PE.

Therefore, a qualitative examination is needed to gain an in-depth understanding of factors influencing each type of teacher's practices and self-efficacy related to the instruction of PE, and what supports and resources they identify as necessary to improve their teaching practices. Additionally, as the teaching profession is dynamic and ever-evolving to meet the diverse learning needs of students, new research is needed in this field. An updated study is warranted, and may help educators, policy makers, and researchers design strategies to support generalists and specialists teaching PE. Therefore, the purpose of this study was to explore the experiences of elementary school generalist and PE specialist teachers when instructing PE, and the barriers and facilitating factors that are perceived by teachers to influence PE teaching practices.

\section{Methods}

Qualitative research methodology was employed to capture rich descriptions and personal accounts of generalist and specialist elementary school teachers' experiences instructing PE. Data were collected from in-depth interviews that were conducted as part of a larger study that utilized an online questionnaire to explore Canadian elementary school generalist and specialist teachers' self-efficacy and perceived barriers when instructing PE. Ethical approval for the study protocol and all related documents was obtained from the Office of Research Ethics at the University of Western Ontario (REB \#110491).

\section{Participants and Recruitment}

Participants were drawn from a pool of elementary school teachers from across Canada who participated in a large exploratory study that utilized an online survey via the platform Qualtrics (C. A detailed account of recruitment for the original study has been 
published elsewhere (Truelove et al., 2019). A total of 1,114 elementary school teachers (818 generalist and $296 \mathrm{PE}$ specialists) completed the online survey and were included in the original study. A subsample of teachers $(n=397)$ indicated at the end of the online survey that they would be interested in taking part in a follow-up interview. Teachers were eligible to participate for an interview if they (1) were a full-time, part-time, or long-term occasional elementary school teacher in Canada; (2) were teaching at least one class of PE a week; (3) spoke English; (4) indicated at the end of the online survey that they were willing to take part in an interview; and (5) agreed to have the interview audio recorded.

Two lists were created, one for generalist teachers $(n=290)$ and one for PE specialist teachers $(n=107)$, and random sampling took place. Teachers on each list were assigned a number, and a list of random numbers was generated for each list using Microsoft Excel to select participants for interviews. Potential participants were invited via email by the first author for a follow-up phone interview. If an individual did not respond to the initial email within one week, the first author contacted the next teacher on the randomized list (working through the two lists of generalists and PE specialists separately). If a teacher confirmed interest in participating, the first author contacted the teacher again to arrange a convenient time for the phone interview to take place. Recruitment took place until theoretical saturation was achieved; that is, a point where further iterations of the data collection and analysis were not necessary because collecting more information would not add to the results (Patton, 2014). A total of 17 generalist teachers and 19 PE specialist teachers were contacted and invited to participate in a follow-up phone interview.

\section{Data Collection}

Teachers verbally consented to participate at the start of the interview and were able to skip questions or end the interview at any time. The audio of all phone interviews was recorded using an Olympus Digital Voice Recorder, and each interview lasted approximately 20-30 minutes. All interviews took place between April and May of 2018.

A semi-structured interview guide developed by the research team was used to ensure consistency across participants, while allowing for flexibility in responses. Questions were phrased to explore the perspectives of generalist and PE specialist teachers 
about their experiences instructing PE, with a particular focus on teaching philosophy, barriers faced when instructing PE, facilitators that enhance PE, and their self-efficacy when teaching PE.

\section{Data Analysis}

Interviews were transcribed verbatim by a professional transcriptionist. Participant anonymity was maintained, and for the purpose of analysis, transcripts were analyzed according to teacher category (generalist [G] versus specialist $[S]$ ). Two coders used deductive content analysis followed by inductive content analysis to code and analyze the transcripts and identify common themes (Elo \& Kyngäs, 2008). Content analysis was used because it is a systematic and objective means to describe and quantify phenomena and allows text of a similar nature to be classified into distinct categories (Downe-Wamboldt, 1992). Initial codes were deductively generated from the literature and interview guide. The first round of coding involved the two coders analyzing the data separately, applying codes, and discussing their results afterwards to reach consensus. If no existing code appropriately captured the data, a new code was developed through inductive content analysis. Intercoder reliability was evaluated using reliability checks throughout the data analysis period (i.e., reviewing disconfirming evidence and debriefing; Creswell \& Plano Clark, 2017). Confirmation bias was addressed as the second coder was not involved in the project directly and was only responsible for coding interviews. A second round of coding was performed by the first author, using "top-level" codes (Elo \& Kyngäs, 2008), to gather similar concepts and identify emergent themes. Throughout the analytical process, quotes within themes were reviewed and scrutinized independently by each author and then discussed to help ensure the trustworthiness of the analysis (Patton, 2014). Trustworthiness (credibility, confirmability, dependability, transferability) was ensured throughout the analytical process. All analyses were completed using QSR NVivo 12.

\section{Results}

The perspectives of 16 elementary school teachers across Canada (eight generalists and eight PE specialists) from five different provinces (Alberta, British Columbia, New 
Brunswick, Nova Scotia, and Ontario) were collected. Participants were mostly female ( $n=14)$ and had been teaching for an average of 15.4 years (range $=2$ to 31 years). Individual participant characteristics are presented in Table 1. On the basis of these data, three overarching concepts were identified which were perceived to influence teaching practices: (1) teaching philosophy and goals for PE, (2) barriers and facilitators (both internal and external), and (3) self-efficacy. The nature of these factors was dependent on the type of teacher providing instruction. Key concepts and categories are summarized in Table 2.

\section{Table 1}

Participant Characteristics of Elementary School Teachers $(n=16)$

\begin{tabular}{|c|c|c|c|c|}
\hline & Sex & Province & $\begin{array}{c}\text { Years of teaching } \\
\text { experience }\end{array}$ & $\begin{array}{l}\text { Self-reported } \\
\text { self-efficacy for } \\
\text { teaching PE } \\
\text { (out of 10) }\end{array}$ \\
\hline \multicolumn{5}{|c|}{ Generalist } \\
\hline 1 & Female & Ontario & 31 & 8 \\
\hline 2 & Female & Ontario & 2 & 5 \\
\hline 3 & Male & Ontario & 6 & 7 \\
\hline 4 & Female & Ontario & 28 & 8 \\
\hline 5 & Female & Ontario & 3 & 6. \\
\hline 6 & Female & Nova Scotia & 24 & 5 \\
\hline 7 & Female & Ontario & 10 & 8 \\
\hline 8 & Female & Ontario & 15 & 7 \\
\hline \multicolumn{5}{|c|}{ PE Specialist } \\
\hline 1 & Female & British Columbia & 4 & 10 \\
\hline 2 & Female & New Brunswick & 12 & 10 \\
\hline 3 & Male & Alberta & 17 & 10 \\
\hline 4 & Female & British Columbia & 17 & 9 \\
\hline 5 & Female & New Brunswick & 11 & 9 \\
\hline 6 & Female & New Brunswick & 26 & 9 \\
\hline 7 & Female & New Brunswick & 11 & 9 \\
\hline 8 & Female & Alberta & 29 & 8 \\
\hline
\end{tabular}

Note. $\mathrm{PE}=$ physical education. 


\section{Table 2}

Factors Influencing Generalist and Specialist Elementary School Teachers Instructing PE

\begin{tabular}{ll}
\hline \multicolumn{1}{c}{ Key factors } & \multicolumn{1}{c}{ Major categories } \\
\hline Teaching philosophy & Remaining active for life $(\mathrm{G}, \mathrm{S})$ \\
and goals & Gaining confidence $(\mathrm{S})$ \\
& Getting exercise $(\mathrm{G}, \mathrm{S})$ \\
& Improving health $(\mathrm{S})$ \\
& Positive attitude towards being active $(\mathrm{S})$ \\
\hline Barriers & Lack of time $(\mathrm{G})$ \\
& Shared facilities $(\mathrm{G}, \mathrm{S})$ \\
& Age appropriate equipment $(\mathrm{G})$ \\
& Inadequate training $(\mathrm{G})$ \\
& Lack of knowledge and experience $(\mathrm{G})$ \\
& Low confidence $(\mathrm{G})$ \\
\hline Facilitators & Professional development opportunities $(\mathrm{G}, \mathrm{S})$ \\
& Technology $(\mathrm{G}, \mathrm{S})$ \\
& Support from specialists and community partners $(\mathrm{G}, \mathrm{S})$ \\
& Background $(\mathrm{G}, \mathrm{S})$ \\
& Training $(\mathrm{S})$ \\
\hline Self-efficacy & Training $(\mathrm{G}, \mathrm{S})$ \\
& Experience $(\mathrm{G}, \mathrm{S})$ \\
& Content dependent $(\mathrm{G})$ \\
& Personal interest $(\mathrm{S})$ \\
\hline
\end{tabular}

Note. The letters in brackets refer to the type of teacher the example refers to, $\mathrm{G}=$ generalist, $\mathrm{S}=$ physical education specialist.

\section{Teaching Philosophy and Goals}

Teachers' philosophies and goals served as the foundation upon which their approach to teaching PE was developed and influenced the way they planned and implemented lessons. When teachers described their goals for PE class and what they hoped their students would take away from their elementary school PE experiences, many focused on concepts such as children being active for life, gaining confidence, getting exercise, improving health, and adopting a positive attitude toward being active. However, as noted above, responses differed according to the type of teacher. 
Specialist teachers most frequently expressed that their goal for PE was to introduce their students to a variety of activities so they could continue to be active throughout their lives. For example, $S 5$ reported their goal for PE: "Students engaging in physical activity... but learning skills that they can utilize throughout their life, and also, enjoying the activities they are doing." In addition, instead of focusing on individual sports, specialist teachers noted that their philosophy of a successful class was one where all students were participating, learning skills, and developing confidence to be active. For example, $S 7$ said (of their idea of a successful class): "Where children are moving, enjoying the physical movements. They are learning a new skill or applying it in a game and I think just overall, building confidence in their ability to move." These teachers looked at students' PE experiences as a whole, and, instead of focusing solely on learning specific sports, they acknowledged that learning the skills and confidence (i.e., physically literate) to remain active for life was an important objective.

When generalists described their teaching philosophy and goals, they often said that a successful lesson would be one in which "the students are moving most of the time and they are engaged" (G5). Less focus was placed on fundamental movement skills and more on ensuring that students were being active during class.

\section{Barriers Faced When Instructing Physical Education}

Three overarching barriers were identified by teachers that were perceived to affect their practices and ability to provide quality PE classes for their students. These included time, facilities and equipment, and training and confidence. Descriptions and examples pertaining to each are detailed below.

Time. The time constraints elementary school teachers face appear to be contingent on their type of qualification. While specialist teachers who instruct PE full-time are only required to focus on one subject, generalist teachers must strategically allocate time to various subjects to meet curricular demands in many areas. As noted by G4: "[Our school board and principal] has really pushed for bringing up our literacy and numeracy marks and assessment grades, so honestly, I don't know how much teachers even really stick to those PE minutes strictly." Typically, PE was deemed a lower priority in comparison to other (academic) subjects, a dilemma that many expressed was unfortunate as they were aware of the positive benefits of activity for their students. Both types of teachers 
commented on the lack of time in the gymnasium as a result of other extenuating circumstances: "Sometimes our gym classes get shortened if we have assemblies and such" (S1); and "During Christmas time, we lose a lot of gym because the stage is down. And during volleyball season, the Grade $7 \mathrm{~s}$ leave the net up in the gym for a month at a time" $(G 1)$.

Facility and equipment. Many teachers noted that the physical environment was a barrier to teaching high quality (and frequent) PE classes. Depending on the size of the school, PE classes were noted to be either infrequent or overcrowded, affecting their ability to reach curriculum requirements of time allocated for PE. For example, one specialist noted:

So definitely the space... and because we only have one gym that, you know, you have to have those double classes with 45 sometimes $50 \mathrm{kids}$, it is definitely a barrier to what you can teach and what you can do and what kinds of games you can play. $(S 8)$

To offset the barrier of only having one gymnasium, some generalist teachers mentioned that their PE class took place in another room within the school.

For me, the limitations are the space. I am not in the big gym. I am in the activity room. So we are limited to certain games and activities based on the physical space. So I might have 28 to 30 five-year-olds running around not in a typical normal sized gym. (G3)

It appears that both types of teachers are limited by the physical space with which they are provided to teach PE and are restricted to activities that large groups can safely participate in a small space. Many teachers felt that sharing the confined space of the gymnasium was a safety concern, as "kids are not spatially aware at this age" (G4). Teachers also mentioned that their gymnasium was used as a mutual space, commonly shared with sport coaches, music and drama clubs, and utilized to host mini tournaments, so gym classes were cancelled frequently.

In terms of equipment, only generalists reported a lack of available equipment in their school as a barrier to instructing PE. In particular, insufficient age-appropriate equipment for the primary grades was reported by some teachers as negatively affecting the ability to teach quality PE: "There seems to be a focus on buying more basketballs, more 
volleyballs, more badminton rackets. The equipment that the older kids use and very little equipment is bought for primary" $(G 1)$. Primary students are still developing their fundamental motor skills, and the equipment needs for this population are unique. Without access to a plentiful supply of age-appropriate equipment, generalist teachers reported that it was difficult to implement new games/activities in their classes: "If I find a game I like online and I go to do it at school and I realize, oh no I only have five hula-hoops and I needed a whole bunch" (G2).

Training and confidence. Almost all generalist teachers indicated that their lack of training and confidence inhibited their ability to provide quality PE classes for their students. Specialists did not indicate such barriers; however, when referring to their generalist colleagues, $S 5$ (a specialist teacher) noted:

For them, I would say a barrier would be knowledge of how to teach. So I think generalists don't know how to necessarily organize their classes and structure it so that they can maximize the time that they have within the space and then often generalist teachers, I would say, are also fearful because they don't know the skills themselves. So, they don't necessarily teach a lot of skills and instead resort to more games.

One teacher went as far to say: "You know, I have had teachers tell me they play dodgeball $80 \%$ of the time" $(S 8)$. Due to the lack of training during their pre-service programs, generalist teachers usually rely on past sport experiences when teaching in this setting; however, this is problematic if a teacher has minimal sport- or physical activity-related experience: "You know, if you don't do a lot of sports, or a lot of physical activities, it's really threatening to teach PE" (G5). This can lead to generalist teachers believing that "PE is a break in the day, and I don't need to plan anything. It's almost like recess" (G3). While the majority of the specialist teachers did not express any barriers in regards to their training or confidence, one shared: "I'm pretty confident in teaching the skills, but my biggest barrier has been teaching kindergarten PE, because my training was heavy set on the older intermediate grades and high school" (S1). With the wide range of curriculum components that need to be taught in elementary school PE, both types of teachers believed they could be better trained when it came to specific units, such as dance, gymnastics, and yoga. 


\section{Facilitators to Instructing Physical Education}

When generalist and specialist teachers were prompted to provide positive factors and resources that contribute to their teaching practices, four overarching themes emerged from the interviews. These included professional development opportunities, technology, support from specialists and community partners, and background and training. Descriptions and examples pertaining to each are detailed below.

Professional development opportunities. Specialist teachers reported that attending workshops and conferences related to PE was extremely valuable to their pedagogy. Although one generalist teacher stated that they participated in workshops made available in order to "educate myself about the various sports and really how to be the very best at teaching PE" (G4), the majority of generalist teachers expressed that they wished they had access to "[a] hands-on workshop or something, to teach us the games and [how] we participate in them" (G2). Specialist teachers indicated that "in the past, we would've met with PE teachers in the region...on professional learning days to discuss different things and share ideas" (S5), "but they've kind of pulled away from that where they just want everyone to be indulged in the literacy or numeracy together [during professional learning sessions]" (S7). Specialists appeared to value the time they had to share ideas with other PE teachers, and noted: "Now it's really hard to get time to actually meet to do things unless it's, you know, after hours" (S7). Generalist teachers did not comment on a lack of focus on PE during professional learning days.

Technology. Both types of teachers frequently reported that they use technology when planning and teaching PE classes. Teachers mentioned websites such as YouTube, Pinterest, Facebook, and Ophea as being excellent resources when teaching PE. The ease of using technology to learn new games was expressed by one generalist teacher:

I'm always resorting to YouTube to kind of watch an example of the game being played instead of just reading instructions online or in a book. I find it's kind of easier to get a better idea of the game that's being played. $(G 2)$

Not only can technology help teachers learn new games and skills, but it can also help students become aware of their movement. As one specialist teacher noted: "We're using a couple programs on the iPad so we can tape movement and then show the kids" (S6). 
Similarly, other specialists integrated technology into their classes to provide visuals for their students, so they could watch an expert perform a certain skill.

Physical education specialists and community partners. Regardless of their accreditation, all teachers believed that having a specialist instruct PE would be more beneficial to their students' motor development. For example, one teacher noted: “They are just able to implement [PE] that much more effectively" (GO). In addition, having a consistent PE teacher during elementary school could help provide students with progressive development of their fundamental movement from year to year. For example, $G 7$ expressed:

I think if we had a PE specialist, like someone running it for the whole school, who was more like qualified to do so, I think it would be a more cohesive experience for them throughout their schooling. Right now, from grade to grade, it's hugely varied and you might cover some skills one year, but not the next and I think having that consistency throughout would help.

S3 iterated that PE "should be taken seriously," and that "whenever possible, we should have people who are trained and have the knowledge necessary to teach PE, because it's not just recess. It's not a period off."

As specialist teachers are not always available to instruct PE, many teachers rely on individuals from the community to teach units with which they are unfamiliar, such as dance, gymnastics, and yoga. Whereas some specialist teachers reported that having community organizations/partners teach their classes provided them the opportunity "to help gain confidence for the future year or give a basis of activities for future teaching" (S5), many generalists noted that they relied on these individuals for current and future classes. For example, $G 2$ shared: “To be honest, I haven’t gone to any effort to give myself more knowledge so that I can teach them. I've just been seeking outside help for that and will continue to seek help."

Background and training. Experience and personal interest in sports seemed to contribute strongly to both types of teachers' practices in PE. Teachers with more experience at the elementary school level reflected that they had learned "what works and doesn't work over the years" (G3). As well, teachers were much more confident 
facilitating a lesson where they were familiar with the sport or activity. Specialists indicated that the training they received during their pre-service schooling and practicum placements shaped their teaching practices, and positively contributed to their ability to provide a high-quality PE experience for their students.

Self-efficacy. The final factor that teachers indicated influenced their teaching practices was their self-efficacy for PE-related instruction. During the interviews, teachers were asked to rate their perceived self-efficacy to teach PE on a scale of 1 to 10, with one being not confident at all, and 10 being extremely confident. On average, generalist teachers self-reported a score of 6.8, while specialists self-reported a score of 9.3. Specialists acknowledged that the additional training they received during their pre-service programs, as well as years of experience teaching in this environment, strongly influenced their self-efficacy to lead high-quality PE classes. Not surprisingly, the generalist teachers with the fewest years of teaching experience in the present study also reported the lowest self-efficacy scores. Moreover, this group of teachers noted that their self-efficacy related to teaching PE was significantly dependent on the content or unit being taught. For example, G4 expressed: "I think absolutely, my confidence changes depending on what activity or what class or unit I have to teach, absolutely, because we are always so much more confident when we're experienced and we're knowledgeable." Contrarily, specialists conveyed high levels of self-efficacy teaching in this environment regardless of the content (e.g., "I feel pretty confident teaching whatever unit it is" [S3]).

\section{Discussion}

The purpose of the present study was to explore the perspectives of generalist and PE specialist teachers when instructing PE, and to examine factors that influence teaching practices. During the interviews, teachers provided extensive information about factors that influence their ability to provide quality PE instruction, and it was clear that many of these factors were dependent on the type of teacher providing the instruction.

With respect to teaching philosophies, generalist and specialist teachers emphasized different outcome goals for their PE classes, which determined the nature of their lessons. It was evident that specialist teachers approached PE as an opportunity to develop students' fundamental movement skills in order to develop physically literate 
individuals capable of sustaining active and healthy lifestyles. Similarly, McEvoy and colleagues (2017) explored the views of 14 PE teachers from seven countries regarding the purpose(s) of PE, and the general consensus was that PE should prepare young people for a lifetime of physical activity. Likewise, a review of 95 qualitative studies that focused on stakeholders' (i.e., teachers, pupils, principals, policy makers) views on the purpose of PE identified children being active and learning physical, social, and emotional skills as outcome goals of PE (Ní Chróinín et al., 2019). Alternatively, the philosophies for generalists in the current study when teaching PE appeared to be centred on keeping children moving throughout their class, with seemingly little regard for developing physical literacy skills. Similarly, in 1983, Placek suggested that keeping students "busy, happy and good" during PE superseded all other learning outcomes for PE. Despite these varying philosophies, research has shown that activity levels during PE are similar when taught by generalist and specialist teachers. In fact, a recent meta-analysis ( $n=39$ studies) conducted by Truelove and colleagues (2019) found that the average percentage of PE class spent in moderate-to-vigorous intensity physical activity (MVPA) was $29.9 \%$ and $33.8 \%$ under the instruction of generalist and specialist teachers, respectively. Acknowledging that PE is an ideal time for children to accumulate minutes of physical activity to benefit their health (Mandigo et al., 2009), it is only one component of a quality PE program (Hardman, 2011).

From a theoretical perspective, PE is not merely an activity or sport, but an academic subject that utilizes physical activity (i.e., movement) as a vehicle to achieve an educational outcome prescribed by the curriculum (Lu \& De Lisio, 2008). Physical literacy is a core element in achieving the overarching goal promoted by a quality PE program, and many believe it must represent the overall goal of every PE class (Whitehead, 2007). Mastering fundamental movement skills and developing confidence to perform these skills during PE is vital for current and future participation in physical activity (Gallahue \& Donnelly, 2007).

Teachers of both classifications also expressed how various factors impeded or facilitated their ability to instruct PE. Generalist teachers noted more negative than positive factors compared to specialists, which highlights the challenges associated with delivering high-quality classes for this distinct group. Barriers faced by generalists are not new findings (Decorby et al., 2005; Morgan \& Bourke, 2005; Morgan \& Hansen, 2008a). As a result of insufficient PE training during pre-service programs (Deacon, 2001), generalists 
have been shown to be at a disadvantage teaching this subject in comparison to specialists and have been found to be reluctant to do so (Hastie \& Martin, 2006). A teacher who has had less training in the field typically exhibits lower confidence (Morgan \& Bourke, 2008; Morgan \& Hansen, 2008b; Xiang et al., 2002), limited knowledge (Decorby et al., 2005), insufficient planning (Decorby et al., 2005), reduced interest and enthusiasm (Morgan \& Hansen, 2008b), and a poorer attitude towards teaching PE (Dwyer et al., 2003), all of which have the capability of affecting the PE experience, and long-term activity habits of their students. The barriers associated with limited training were also expressed by the generalist teachers in this study. If generalist teachers are going to continue to be required to teach $\mathrm{PE}$ at the elementary school level, it is critical that they are trained properly to reduce teacher-related barriers and ensure the students under their supervision are developing the skillset and confidence to remain active for life.

Generalist teachers in the current study indicated that there was pressure from their school board and principals to focus on subjects like math and language to improve numeracy and literacy skills of their students, leaving minimal (if any) time for PE class. The time constraints faced by generalist teachers are unique. Time devoted to one academic subject in turn reduces the amount of available time for other curricular subjects. In fact, the length of PE lessons taught by generalists has been found to be shorter in comparison to classes taught by specialists (Sallis et al., 1997). Conversely, specialists are only responsible for teaching one subject, generating no competing academic demands. In a study conducted by Barroso and colleagues (2005), specialist teachers ranked insufficient time in the school day as the second-lowest perceived barrier to teaching PE (out of eight options) for four straight years. Specialists do not have to intricately plan their day to make time for multiple subjects, or factor in transition time from the classroom or recess to the gymnasium. To help alleviate this barrier for generalist teachers, it is imperative that they are supported to accommodate PE into their weekly schedule. One solution that has been frequently suggested in the literature and has been successful in increasing students' daily physical activity levels is showing teachers how to integrate physical activity within the classroom (Adams-Blair \& Oliver, 2011; McMullen et al., 2019).

Both generalists and specialists in the current study identified the physical environment as a major barrier when trying to teach a quality PE program. Large class sizes coupled with small spaces creates a safety concern, especially when children are still developing their motor skills and spatial awareness (Barroso et al., 2005). Teachers 
are legally responsible for ensuring that safe conditions are provided in their PE classes (Manitoba Physical Education Teachers' Association, 2001). Unfortunately, generalist teachers may not be trained to minimize safety concerns or be aware of their responsibilities, nor realize potential hazards that are inherent to physical activity environments (Decorby et al., 2005). Safety is an issue that must be addressed proactively in all schools, starting with ensuring the space provided for PE is large enough for the number of students and the activity being played. Unfortunately, findings from Hardman and Marshall's (2000) international survey on the state and status of PE indicated that $69 \%$ of PE facilities globally are inadequate (58\% in the United States, and $87 \%$ in Canada). The level of provision, together with challenges presented by inadequate maintenance of facilities, can detrimentally influence the nature, scope, and quality of PE programs. As such, it is near impossible to expect even the best-prepared teachers to instruct high quality (and safe) classes when the space provided is inadequate. One solution to overcoming large class sizes and inadequate facilities in PE is to utilize other environments, for example outdoor spaces and multi-purpose classrooms.

Equipment is also an area of deficiency when teaching elementary school PE. Specifically, access to age-appropriate equipment is a common barrier listed by generalist teachers (Jenkinson \& Benson, 2010; Morgan \& Hansen, 2008a). As mentioned previously, elementary school students are in the process of developing their fundamental motor skills (Morgan et al., 2013). Thus, standard equipment (which is typically plentiful in supply), such as racquets, volleyballs, and standard basketball nets are inappropriate for younger students, as they do not allow children to be successful in their movements. Without an ample supply of equipment that is suitable for younger students (e.g., pool noodles, beach balls, bean bags), generalist teachers have been noted to struggle with adapting traditional games to their younger pupils (Morgan \& Hansen, 2008b; Truelove et al., 2019). Lack of resources and equipment also make it difficult to work on individual skills, affecting skill acquisition (Decorby et al., 2005). On the other hand, specialist teachers have been found to perceive insufficient equipment and resources as only a minor barrier affecting their quality of instruction (Barroso et al., 2005; Truelove et al., 2019). In this study, specialist teachers noted that their experience teaching in this environment left them better off when equipment was scarce, as they were more creative and resourceful when improvising activities using similarly shaped or sized pieces of equipment. In order to combat this barrier, teachers' lessons should be planned in advance 
in accordance with the available equipment at their school, and equipment needs for PE should be brought to the attention of the school principal.

There were also many positive factors that teachers indicated as supportive of their efforts to provide high quality PE experiences for their students. Specialists in this study articulated how valuable attending conferences, workshops, and professional development days were to their pedagogy, while generalist teachers expressed their interest in taking part in hands-on workshops to improve their PE-related self-efficacy and expand their skill repertoire. Partaking in professional development opportunities, such as workshops and conferences focused on PE, have been shown to heighten teachers' confidence teaching in this environment (Jess \& McEvilly, 2015; Martin et al., 2008; Sallis et al., 1997). While even limited professional development, such as a one-day workshop, can positively impact teachers' self-efficacy (Martin et al., 2008), a host of general education studies have shown that ongoing professional development leads to substantially higher increases in teacher efficacy (Jess \& McEvilly, 2015; Vannatta \& Nancy, 2004; Watson, 2006). Unfortunately, generalist teachers have been found to participate in comparatively little PE professional development than other core subjects (e.g., mathematics and literacy), and what they have encountered has often lacked depth and challenge, and displayed limited coherence, relevance, and progression (Armourand \& Yelling, 2004; Armour et al., 2012). Moreover, conferences concentrated on PE are typically only attended by PE specialists, thereby widening the gap between generalists' and specialists' confidence and knowledge instruction in this environment. To improve generalists' self-efficacy and knowledge teaching in this unique environment, ongoing opportunities for professional development need to be available to both types of teachers, and there should be support from principals and school board officials for teachers to take part in these sessions.

Specialists in the current study noted that the use of technology during their classes was extremely beneficial to their students' learning, as the students could visualize their movements and compare their performance to a more skilled model with a particular focus on identifying key features of the technique. The use of technology within the field of PE, by means of access to resources online, or integration of digital technology within the PE, has enormous potential to support teachers to provide high-quality PE experiences for their students (Wyant \& Baek, 2019). As technology is now a major part of the modern learning landscape, teachers are continuously seeking new methods to integrate digital learning resources and support into PE classes (Hyndman, 2017b; Kim et al., 
2006). Technology can also be useful for teachers to gather new ideas and network with other teachers. For example, generalists and specialists in the current study conveyed that access to free online platforms such as YouTube, Pinterest, and Facebook has helped them expand their repertoire of games and activities, which in turn keeps their students motivated and engaged in PE classes.

Support from teachers specifically trained in PE has also been acknowledged as beneficial to generalist teachers faced with the task of teaching their own PE (Faucette et al., 2002; Truelove et al., 2019). For example, Faucette and colleagues (2002) explored the effect of a two-year professional development program (Project SPARK) led by specialists on 16 generalist teachers' self-confidence when teaching PE. After the program, qualitative data indicated that frequent support by a specialist, and modelling classes of a specialist were extremely valuable in increasing the generalist teachers' self-confidence when teaching PE. Outsourcing PE to external providers was noted as common practice by both types of teachers in the current study. This form of content delivery can be an effective method for offering elementary school students specialist instruction, as well as providing training for teachers (Sperka \& Enright, 2018).

However, generalist teachers in the present study indicated that their use of external providers in PE was purely to replace themselves, rather than to support their efforts teaching in this environment. While schools and teachers have been seen to accept and often embrace the role of external providers in delivering PE due to their perceived content expertise, there is limited to no evidence that external providers have the pedagogical or curricular knowledge or skills to construct experiences that address curricular outcomes (Sperka \& Enright, 2018). External providers should be used as a support mechanism and supplement teachers teaching in this environment (as the specialists reported in this study), rather than a substitute to ensure students are still receiving instruction from someone qualified in the profession.

\section{Limitations}

A number of limitations must be acknowledged. First, interviews were only conducted in English; this may have discouraged/excluded teachers from Quebec from taking part (as French is the dominant language in that province). Secondly, the majority of study participants were female. While the majority of teachers at the elementary school level 
in Canada are female (83.6\%; Statistics Canada, 2015), this subgroup has also been found to have lower self-efficacy teaching PE (Truelove et al., 2019). Additionally, while efforts were taken to capture diverse perspectives by recruiting through randomization, the majority of the generalist teachers were from one province (Ontario). As education is regulated at the provincial level, policies within the province regarding the training and education of teachers and implementation of PE in schools could have influenced the findings. Despite efforts to recruit a large sample from all provinces/territories, a larger, more diverse sample from across the country is necessary to alleviate these concerns, and increase the transferability of the findings. Furthermore, as information was collected via interviews, social desirability bias could have affected the findings, as teachers may have been more likely to perceive that institutional barriers had an adverse impact on their efforts to teach PE rather than attribute a lack of success to their own shortcomings.

\section{Conclusion}

This research is the first qualitative study to highlight how Canadian elementary school teachers' specialization affects their daily experiences teaching PE classes, specifically with regard to teaching philosophies, barriers and facilitators, and self-efficacy. It was evident that a number of perceived barriers inhibited generalist teachers' efforts and capacity to implement regular and developmentally appropriate PE lessons. Of concern, many of the barriers expressed by generalists in the current study were noted internationally more than 10 years ago (Barroso et al., 2005; Decorby et al., 2005; Morgan \& Bourke, 2008; Morgan \& Hansen, 2008a). Despite over a decade of research, there have been no radical changes to improve the landscape for individuals required to teach in this setting. This qualitative exploration of factors that influence generalists' and specialists' experiences in PE might help provide clarification as to what additional training, support, and resources are desired and needed, and serves as a call to action to improve the teaching landscape for teaching physical education in Canada. In addition, insights to what specialists perceive as having positive impacts on their teaching practices, such as advanced training, professional development opportunities, heightened self-efficacy, and use of technology, may help direct researchers, policy makers, and educators to tailor resources to support generalists teaching in this unfamiliar setting, closing the gap 
between the qualities of instruction between the two types of teachers. Based on these findings, it appears that generalist teachers may be at a disadvantage teaching PE due to lack of training, experience, and self-efficacy in this environment, coupled with the responsibility of teaching multiple curricular priorities. If generalist teachers are going to continue to be required to instruct $\mathrm{PE}$ at the elementary school level, it is essential that they have the knowledge, confidence, and support necessary to be successful teaching in this subject area. Improved (and tailored) pre-service training and ongoing professional development opportunities for in-service teachers could help ensure that all individuals responsible for teaching $\mathrm{PE}$ are properly trained to handle the unique demands of teaching in this setting. 


\section{References}

Adams-Blair, H., \& Oliver, G. (2011). Daily classroom movement: Physical activity integration into the classroom. International Journal of Health, Wellness \& Society, 1(3), 147-154.

Armour, K., Makopoulou, K., \& Chambers, F. (2012). Progression in physical education teachers' career-long professional learning: Conceptual and practical concerns. European Physical Education Review, 18(1), 62-77. https://doi. org/10.1177/1356336X11430651

Armourand, K. M., \& Yelling, M. (2004). Professional development and professional elearning: Bridging the gap for experienced physical education teachers. European Physical Education Review, 10(1), 71-93. https://doi. org/10.1177/1356336X04040622

Ashton, P. (1984). Teacher efficacy: A motivational paradigm for effective teacher education. Journal of Teacher Education, (5), 28-32. https://doi. org $/ 10.1177 / 002248718403500507$

Bandura, A. (1989). A social cognitive theory of action. In J. P. Forgas \& J. M. Innes (Eds.), Recent advances in social psychology: An international perspective (pp. 127-138). Elsevier.

Barroso, C. S., McCullum-Gomez, C., Hoelscher, D. M., Kelder, S. H., \& Murray, N. G. (2005). Self-reported barriers to quality physical education by physical education specialists in Texas. Journal of School Health, 75(8), 313-319. https://doi. org/10.1111/j.1746-1561.2005.00042.x

Buschner, C. A. (1984). Teaching elementary physical education: Whose responsibility? Education, 105(1), 34-39.

Chase, M. A., Lirgg, C. D., \& Carson, R. L. (2001, March). Development of the physical education teacher efficacy scale: Evaluation of reliability, concurrent and construct validity [Conference presentation]. American Alliance of Health, Physical Education, Recreation, and Dance Conference, Cincinnati, OH, United States. 
Creswell, J. W., \& Plano Clark, V. L. (2017). Designing and conducting mix methods research. Sage. https://doc1.bibliothek.li/aca/FLMF022364.pdf\%0Ahttp://doc1. bibliothek.li/aca/FLMF022364.pdf

Davis, K. S., Burgeson, C. R., Brener, N. D., McManus, T., \& Wechsler, H. (2005). The relationship between qualified personnel and self-reported implementation of recommended physical education practices and programs in U.S. schools. Research Quarterly for Exercise and Sport, 76(2), 202-211. https://doi.org/10.108 $\underline{0 / 02701367.2005 .10599281}$

Deacon, B. W. (2001). Physical education curriculum review report. Ministry of Education, Curriculum Branch. http://www.llbc.leg.bc.ca/public/pubdocs/ bcdocs $/ 361630 /$ pereport.pdf

Decorby, K., Halas, J., Dixon, S., Wintrup, L., \& Janzen, H. (2005). Classroom teachers and the challenges of delivering quality physical education. The Journal of Educational Research, 98(4), 208-221. https://doi.org/10.3200/ JOER.98.4.208-221

Downe-Wamboldt, B. (1992). Content analysis: Method, applications, and issues. Health Care for Women International, 13(3), 313-321. https://doi. org/10.1080/07399339209516006

Dwyer, J. J. M., Allison, K. R., Hansen, B., Goldenberg, E., \& Boutilier, M. (2003). Teachers' perspective on barriers to implementing physical activity curriculum guidelines for school children in Toronto. Canadian Journal of Public Health, 94(6), 448-452. https://link.springer.com/article/10.1007/BF03405083

Elo, S., \& Kyngäs, H. (2008). The qualitative content analysis process.

Journal of Advanced Nursing, 62(1), 107-115. https://doi. org/10.1111/j.1365-2648.2007.04569.x

Faucette, N., Nugent, P., Sallis, J. F., \& McKenzie, T. L. (2002). “I'd rather chew on aluminum foil:" Overcoming classroom teachers' resistance to teaching physical education. Journal of Teaching in Physical Education, 21(3), 287-308. https://doi. org/10.1123/jtpe.21.3.287

Gallahue, D. L., \& Donnelly, F. C. (2007). Developmental physical education for all children. Human Kinetics. 
Hardman, K. (2011). Global issues in the situation of physical education in schools. In K. Hardman \& K. Green (Eds.), Contemporary issues in physical education: International perspectives (pp. 11-29). Meyer \& Meyer.

Hardman, K., \& Marshall, J. (2000). The state and status of physical education in schools in international context. European Physical Education Review, 6(3), 203-229. https://doi.org/10.1177/1356336X000063001

Hardman, K., \& Marshall, J. (2014). World-wide survey of school physical education: Final report. Unesco. https://unesdoc.unesco.org/ark:/48223/pf0000229335

Hastie, P. A., \& Martin, E. H. (2006). Teaching elementary physical education: Strategies for the classroom teacher. Pearson.

Hyndman, B. P. (2017a). A simulation pedagogical approach to engaging generalist preservice teachers in physical education online: The GoPro trial 1.0. Australian Journal of Teacher Education, 42(1), 84-102. https://doi.org/10.14221/ ajte. $2017 \mathrm{v} 42 \mathrm{n} 1.6$

Hyndman, B. P. (2017b). Perceived social-ecological barriers of generalist pre-service teachers towards teaching physical education: Findings from the GET-PE study. Australian Journal of Teacher Education, 42(7). https://doi.org/10.14221/ ajte. $2017 \mathrm{v} 42 \mathrm{n} 7.3$

Jenkinson, K. A., \& Benson, A. C. (2010). Barriers to providing physical education and physical activity in Victorian state secondary schools. Australian Journal of Teacher Education, 35(8), 1. http://dx.doi.org/10.14221/ajte.2010v35n8.1

Jess, M., \& McEvilly, N. (2015). Traditional and contemporary approaches to careerlong professional learning: a primary physical education journey in Scotland. Education 3-13, 43(3), 225-237. https://doi.org/10.1080/03004279.2013.804851

Kilborn, M., Lorusso, J., \& Francis, N. (2016). An analysis of Canadian physical education curricula. European Physical Education Review, 22(1), 23-46. https:// doi.org/10.1177\%2F1356336X15586909

Kim, K.-J., Bonk, C. J., Teng, Y., Son, S. J., Zeng, T., \& Oh, E. J. (2006, October). Future trends of blended learning in workplace learning across different cultures [Paper presentation]. Association for Educational Communications and Technology 
(AECT) 2006 Annual International Convention, Dallas, TX. https://members.aect. org/pdf/Proceedings/proceedings06/2006/06_18.pdf

Lu, C., \& De Lisio, A. (2008). Exploring the relationship between physical education and physical activity. Teaching and Learning, 4(3). https://doi.org/10.26522/ tl.v4i3.263

Mandigo, J., Francis, N., Lodewyk, K., \& Lopez, R. (2009). Position paper: Physical literacy for educators. Physical and Health Education Canada. https://phecanada. ca/sites/default/files/content/docs/resources/pl_position_paper.pdf

Mandigo, J. L., Thompson, L. P., Spence, J. C., Melnychuk, N., Schwartz, M., Dunn, J. C., \& Marshall, D. (2004). A descriptive profile of physical education teachers and related program characteristics in Alberta. Alberta Journal of Educational Research, 50(1), 87-102.

Manitoba Physical Education Teachers' Association. (2001). Manitoba safety guidelines for physical education. Manitoba Physical Education Teachers' Association.

Martin, J. J., Mccaughtry, N., Hodges-Kulinna, P., \& Cothran, D. (2008). The influences of professional development on teachers' self-efficacy toward educational change. Physical Education \& Sport Pedagogy, 13(2), 171-190. https://doi. org/10.1080/17408980701345683

McEvoy, E., Heikinaro-Johansson, P., \& MacPhail, A. (2017). Physical education teacher educators' views regarding the purpose(s) of school physical education. Sport, Education and Society, 22(7), 812-824. https://doi.org/10.1080/13573322.2015.1 075971

McKenzie, T. L., Sallis, J. F., Faucette, N., Roby, J. J., \& Kolody, B. (1993). Effects of a curriculum and inservice program on the quantity and quality of elementary physical education classes. Research Quarterly for Exercise and Sport, 64(2), 178-187. https://doi.org/10.1080/02701367.1993.10608795

McMullen, J. M., MacPhail, A., \& Dillon, M. (2019). “I want to do it all day!"Students' experiences of classroom movement integration. International Journal of Educational Research, 94, 52-65. https://doi.org/10.1016/j.ijer.2018.11.014

Morgan, P., \& Bourke, S. (2005). An investigation of pre-service and primary school teachers' perspectives of PE teaching confidence and PE teacher education. 
ACHPER Healthy Lifestyles Journal, 52(1), 7-13. https://pdfs.semanticscholar. org/d642/bf89345c18a602110052082483896d69f34e.pdf

Morgan, P., \& Bourke, S. (2008). Non-specialist teachers' confidence to teach PE: The nature and influence of personal school experiences in PE. Physical Education \& Sport Pedagogy, 13(1), 1-29. https://doi.org/10.1080/17408980701345550

Morgan, P. J., Barnett, L. M., Cliff, D. P., Okely, A. D., Scott, H. A., Cohen, K. E., \& Lubans, D. R. (2013). Fundamental movement skill interventions in youth: A systematic review and meta-analysis. Pediatrics, 132(5), e1361-e1383. https:// doi.org/10.1542/peds.2013-1167

Morgan, P. J., \& Hansen, V. (2008a). Classroom teachers' perceptions of the impact of barriers to teaching physical education on the quality of physical education programs. Research Quarterly for Exercise and Sport, 79(4), 506-516. https://doi. org/10.1080/02701367.2008.10599517

Morgan, P. J., \& Hansen, V. (2008b). The relationship between PE biographies and PE teaching practices of classroom teachers. Sport, Education and Society, 13(4), 373-391. https://doi.org/10.1080/13573320802444994

National Association for Sport and Physical Education. (2012). 2012 shape of the nation report: Status of physical education in the USA. American Alliance for Health. https://www.shapeamerica.org/advocacy/son/2012/upload/2012-Shape-of-Nationfull-report-web.pdf

Ní Chróinín, D., Fletcher, T., Jess, M., \& Corr, M. (2019). A major review of stakeholder perspectives on the purposes of primary physical education. European Physical Education Review, 26(2), 322-336. https://doi.org/10.1177/1356336X19856381

Ontario Physical and Health Education Association (Ophea). (2016). Evidence energizer: Physical activity in the elementary school setting. Ontario Physical and Health Education Association. https://parc.ophea.net/sites/parc-dev.ophea.net/files/PARC/ PARC_EvidenceEnergizer_Access_03FE17.pdf

Pan, Y.-H. (2014). Relationships among teachers' self-efficacy and students' motivation, atmosphere, and satisfaction in physical education. Journal of Teaching in Physical Education, 33(1), 68-92. https://doi.org/10.1123/jtpe.2013-0069 
Pate, R. R., Davis, M. G., Robinson, T. N., Stone, E. J., McKenzie, T. L., \& Young, J. C. (2006). Promoting physical activity in children and youth: A leadership role for schools: A scientific statement from the American Heart Association Council on Nutrition, Physical Activity, and Metabolism (Physical Activity Committee) in collaboration with the Councils on Cardiovascular Disease in the Young and Cardiovascular Nursing. Circulation, 114(11), 1214-1224. http://circ.ahajournals. org

Patton, M. Q. (2014). Qualitative research \& evaluation methods (4th ed.). Sage.

People for Education. (2018). The new basics for public education. People for Education. https://peopleforeducation.ca/wp-content/uploads/2018/06/AnnualReport18_Web. pdf

Placek, J. (1983). Conceptions of success in teaching: Busy, happy and good? In T.

J. Templin \& J. K. Olson (Eds.), Teaching in physical education (pp. 46-56). Human Kinetics.

Sallis, J. F., McKenzie, T. L., Alcaraz, J. E., Kolody, B., Faucette, N., \& Hovell, M. F. (1997). The effects of a 2-year physical education program (SPARK) on physical activity and fitness in elementary school students. Sports, play and active recreation for kids. American Journal of Public Health, 87(8), 1328-1334. https:// doi.org/10.2105/AJPH.87.8.1328

Sperka, L., \& Enright, E. (2018). The outsourcing of health and physical education: A scoping review. European Physical Education Review, 24(3), 349-371. https:// doi.org/10.1177/1356336X17699430

Statistics Canada. (2015). Women in teaching-related professions, Canada, 1996 and 2006: Table 13. https://www150.statcan.gc.ca/n1/pub/89-503-x/2010001/ article/11542/tbl/tbl013-eng.htm

Telford, R. M., Olive, L. S., Cochrane, T., Davey, R., \& Telford, R. D. (2016). Outcomes of a four-year specialist-taught physical education program on physical activity: A cluster randomized controlled trial, the LOOK study. International Journal of Behavioral Nutrition and Physical Activity, 13(1), 64. https://doi.org/10.1186/ s12966-016-0388-4 
Thompson, L., Spence, J. C., Mandigo, J., Marshall, D., Causgrove Dunn, J., Schwartz, M., \& Melnychuk, N. (2001). Alberta physical education study (ALPES): Final report. University of Alberta. https:/www.centre4activeliving.ca/media/filer public/36/95/369564ef-e3bc-43d3-86f6-dca35e8bfbc6/2001-alberta-ped-study.pdf

Truelove, S., Johnson, A. M., Burke, S. M., \& Tucker, P. (2019). Comparing Canadian generalist and specialist elementary school teachers' self-efficacy and barriers related to physical education instruction. Journal of Teaching in Physical Education, 1(aop), 1-11. https://doi.org/10.1123/jtpe.2019-0091

Vannatta, R. A., \& Nancy, F. (2004). Teacher dispositions as predictors of classroom technology use. Journal of Research on Technology in Education, 36(3), 253-271. https://doi.org/10.1080/15391523.2004.10782415

Watson, G. R. (2006). Technology professional development: Long-term effects on teacher self-efficacy. Journal of Information Technology for Teacher Education, 14(1), 151-165. https://pdfs.semanticscholar.org/a6b6/ ac9924fd66da0f4207f909d7a897d473fa5d.pdf

Whitehead, M. (2007). Physical literacy: Philosophical considerations in relation to developing a sense of self, universality and propositional knowledge. Sports Ethics and Philosophy, 1(3), 281-298. https://doi. org/10.1080/17511320701676916

Wyant, J., \& Baek, J.-H. (2019). Re-thinking technology adoption in physical education. Curriculum Studies in Health and Physical Education, 10(1), 3-17. https://doi.org /10.1080/25742981.2018.1514983

Xiang, P., Lowy, S., \& Mcbride, R. (2002). The impact of a field-based elementary physical education methods course on preservice classroom teachers' beliefs. Journal of Teaching in Physical Education, 21, 145-161. https://doi.org/10.1123/ jtpe.21.2.145 